\title{
External Quality Assessment Practices in Clinical Biochemistry Laboratory: What is the need? Niraula A, ${ }^{1}$ Bataju $\mathrm{M}^{2}$
}

${ }^{1}$ Department of Biochemistry,

BP Koirala Institute of Health Sciences,

Dharan, Nepal.

${ }^{2}$ Department of Biochemistry,

KIST Medical College and Teaching Hospital,

Lalitpur, Nepal.

\section{Corresponding Author}

Apeksha Niraula,

Department of Biochemistry,

BP Koirala Institute of Health Sciences,

Dharan, Nepal.

E-mail: apeksha.niraula@bpkihs.edu

Citation

Niraula A, Bataju M. External Quality Assessment Practices in Clinical Biochemistry: What is the need? Kathmandu Univ Med J. 2020;69(1):86-92.

\section{ABSTRACT}

Health Care services is considered as an amalgamation between the doctor undergoing the examination and laboratory personnel behind the proper diagnosis of the patient. It has evolved to a large extent from a simple process of examination to handling the prescription to the patient. During this evolution, there has been a remarkable development in the field of laboratory diagnosis. A good laboratory is abided by the rule of quality services including quality control; both internal and external. External quality assessment program contributes to the long term accuracy of the analytical method used by the laboratory. It determines the number of quality element of the practicing laboratory and helps in the upliftment of the status of the laboratory to laboratory accreditation and certification. This review article is intended to review the importance of the external quality assessment program over internalquality control, its need in the laboratory and the current practices in externalquality assessment. Medline search was done for the articles published in English language from 1945 to 2018. Keywords employed to search the articles were external quality assessment, EQA programs, quality assurance, and quality control in clinical biochemistry, respectively. We searched for any articles with the details of external quality assessment tools that were original articles, review, editorial and the official website of the EQAS program. The unavailable articles were searched through research gate and the authors were requested for full text. A total of 5 full text original research article were found and rest of the articles like review article, editorial, national policy were studied in detail. Standard textbooks for clinical chemistry and chapters for EQA under quality assurance was reread in detail. Studies and policy makers have depicted that External Quality Assessment scheme (EQAS) as an integral component for the efficient and high quality laboratory operation. The western countries haizve their own laboratory accreditation body which conducts the EQAS program and offers participation to other clinical laboratories. Countries in South East Asia have shown to be burgeoning in the field of EQA program with establishment of their own laboratory accreditation bodies and incorporating the non-accredited laboratories in EQA programs.

\section{KEY WORDS}

External quality assessment programs, Quality assurance, Quality control in clinical biochemistry, Quality Improvement 


\section{INTRODUCTION}

Though, a clinical biochemist have the knowledge regarding the quality control in clinical chemistry laboratory, but it is the most under discussed and overshadowed topic in terms of the practical application of quality control i.e. Internal and External quality control in the clinical biochemistry laboratory.

\section{Transformation in External Quality assessment scheme (EQAS) from $20^{\text {th }}$ Century:}

The evolution of External Quality assessment (EQA) began from late 1940 s pioneered by Belk and Sunderman. ${ }^{1}$ We have come a long way, where in today's era EQA constitutes an integral component for the laboratory total quality management system. In addition, it is a fundamental element for laboratory accreditation in many countries around the world..$^{2-3}$ It is the responsibility of the personnel associated with EQA to verify on a recurring basis that laboratory results conform to expectations for the quality required for patient care. ${ }^{3}$

In general, quality management system (QMS) is the set of coordinated activities conceded out on a set of elements to achieve the quality of the products or services offered to the users. ${ }^{4}$ It plans, controls and improves the elements that impact on the achievement of the desired results by the laboratory and on the satisfaction of the customers or users..$^{4-7}$ Specifically in context to medical laboratories, QMS is directed towards the accuracy, reliability, and timeliness of the analytical results of the laboratory. Thus, the quality of the laboratory results is directly dependent on the aspects of the analytical operations which must be under stringent control. ${ }^{4-6}$ ISO 9001:2015 precisely define QMS individually as. ${ }^{4,8-12}$

\section{Quality}

Degree comprising of a set of essential characteristics of an object (product, service, process, person, resource, etc.) which meet the requirements (established need or expectation, generally implicit or mandatory)

\section{Management}

Coordinated activities to direct and control an organization

\section{System}

A set of interrelated elements.

\section{What is External Quality Assessment: Current Practice?}

External Quality Assessment (EQA) is a continuous process for quality improvement in which the participating laboratory uses an outside unbiased source to verify the quality of patient's results. ${ }^{13-18}$ Participating in an EQA program permits a laboratory to confirm that its results are consistent with those of other laboratories using the same or similar methods for an analyte and thus to confirm it is using a method correctly. ${ }^{7-9}$ EQA is an imperative aspect for any laboratory operation to maintain the good quality laboratory practice and smooth operation. It offers the means of for the assessment of the analytical performance of the particular laboratory which is directly compared to the other participating laboratory (also called as peer groups) employing the similar method and instrument for the measurement of the analyte. ${ }^{5,10,11}$ EQA measures blind samples ie. the sample with unknown value and treated as patient samples unlike the control sample used in internal quality control where the value is known. The results is subsequently returned to the EQA provider for the statistical analysis comparing it with the peer laboratory group. ${ }^{10-12}$ The participating laboratories obtain the report comparing the individual laboratory performance with the other participant laboratory in the EQA programme. ${ }^{13,19-21}$

Few benefits of participating in EQA programme. ${ }^{13,22}$

- Crucial for maintaining the long-term accuracy of the analytical methods

- Validation of analytical method

- Comparison of the results with other laboratories

- Identification of problem related to tests

- Mandatory requirement for laboratory accreditation

The purpose of implementing EQA programme in the clinical biochemistry laboratory ${ }^{13,22,24}$ :

- Evaluation of laboratory performance for specific tests and its continuous monitoring

- Identification of inter- laboratory differences

- Evaluation of method/diagnostic system performances

- Degree of comparability between methods/diagnostic systems

- Monitoring of the success of harmonization/ standardization efforts for improving results comparability

One of the major component to be looked for in an EQA programme is a process of harmonization is in order to make participation in EQA effective and to guarantee the congruity of EQA information provided by different providers. ${ }^{18,19,24-29}$

\section{Methodology in EQA}

There are basically four different stages in an EQA programme starting from sending the quality control material (QC) to the participating laboratory to the interpretation of the EQA results. The phases can be depicted as follows. ${ }^{30-33}$

Providing and sending quality control (qc) material to participating laboratory

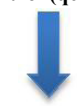

Measuring analyte(s) and reporting result(s) by participating laboratory

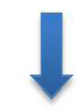

Data analysis and sending evaluation report(s) to participating laboratory

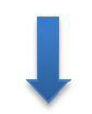

Interpretation of evaluation report(s) and taking corrective action for unacceptable result(s) in participating laboratory 
The EQA process can be summarized in a cyclical manner which can also be called as an EQA cycle. ${ }^{34-36}$

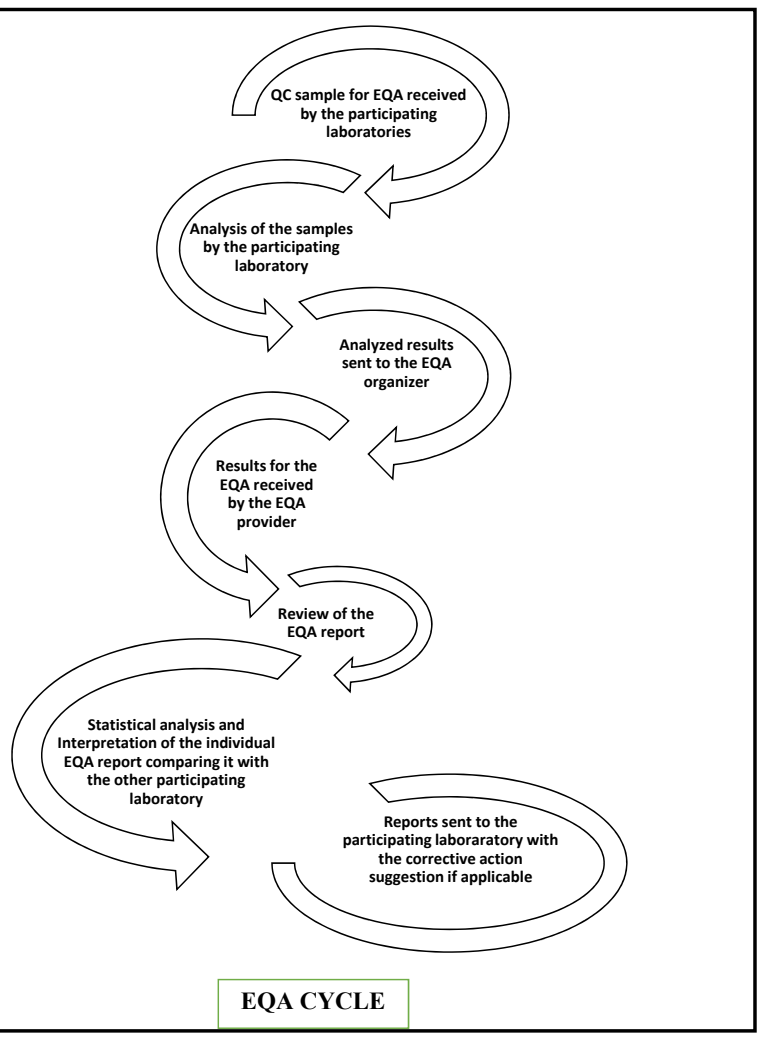

\section{Need of EQA in clinical laboratories}

In today's era, quality is trending in every aspect of human life. ${ }^{4,7,8}$ The impact of quality in terms of laboratory results have acquired a new aspect. Most of the clinical laboratories are concerned with their results in terms of its accuracy, precision and timeliness. ${ }^{37,38}$ Clinical biochemistry laboratories are aware of undertaking internal quality control daily or on their sample load to maintain their precision and short term accuracy of the laboratory results. Inspite of the cognizance regarding the EQA in clinical laboratory, number of them have not incorporated in their practice ${ }^{39-41}$ There is a definite question that arises regarding the usefulness of EQA in addition to internal quality control in clinical biochemistry. There are certain advantages of EQA which enables it to be a pre-requisite for good quality practice in the laboratory. ${ }^{7}$

Internal quality control is the means of maintaining the daily precision and accuracy of the particular analytical method. ${ }^{38}$ While, EQA is crucial important for maintaining the long term accuracy of the analytical methods. Also, it is imperious for validation of analytical method and comparison of the results with other laboratories. ${ }^{42-44}$ EQA is a mandatory requirement for laboratory accreditation and certification of the authorized body. ${ }^{12,45,46}$

\section{Proficiency testing or EQA: Is there any difference?}

Proficiency testing or EQA has been used synonymously most of the time by the experts. ${ }^{47}$ Closely observed these two terms are slightly different in terms of their applicability. ${ }^{48}$ Though, the idea behind proficiency testing and an EQA is to maintain the good quality practice in the medical laboratory, but the practical aspects are distinct. ${ }^{10}$

Proficiency testing is used for evaluation of laboratory performance for regulatory purposes. ${ }^{47}$ Laboratories participating in the proficiency testing provided by the EQA provider states the quality of the clinical laboratory over the month and year and can also suggest the corrective action wherever needed. ${ }^{48}$

External Quality Assessment Schemes (EQAS) is the process used for laboratory performance and method evaluation. The purpose is usually educational. ${ }^{49}$

External Quality Assessment Programmes (EQAP) is the scheme where inter-laboratory comparisons designed and operated to assure one or more of the following ${ }^{47-49}$ :

- Participant performance-analytical, interpretive, clinical advice

- Method performance evaluation

- In vitro diagnostic device vigilance

- Education

- Training and help

What are the points to be looked for in an EQA program?

EQA programme is a certified programme which can only be started by an accredited laboratory to undertake other laboratories for proficiency testing.47 Firstly, the EQA program should be chosen on the basis of convenience and reliability by the particular laboratory. Few points can be enlisted to be beheld for in an EQA10:

- Sample design and frequency

- Analytical goals

- Easy to read reports

- Scientific validity and reliability

- Education

- Scientific support

Interpretation of EQA Results ${ }^{49}$ :

1. Standard Deviation Index (SDI) Chart: The standard deviation index is a measurement of bias. It determines that how close is your laboratory value to the target value.

It is calculated as SDI = (Laboratory Mean - Group Mean)/ Group Standard Deviation

\section{Interpretation}

\begin{tabular}{ll}
\hline 0.0 & Perfect Comparison with the consensus group \\
$\mathbf{1} 1.25$ & Acceptable \\
\hline $1.25-1.49$ & $\begin{array}{l}\text { Acceptable to marginal performance. Some investigation } \\
\text { of the test system may be required }\end{array}$ \\
\hline $1.5-1.99$ & $\begin{array}{l}\text { Marginal Performance. Investigation of the test system is } \\
\text { recommended. }\end{array}$ \\
\hline 22.0 & $\begin{array}{l}\text { Unacceptable Performance. Remedial action usually } \\
\text { required. }\end{array}$ \\
\hline
\end{tabular}


2. Variance Index Score (VIS): Calculated as

\%VARIATION = (Difference between participant's result and Group mean $\times 100) /$ Group mean

VARIANCE INDEX SCORE(VIS) $=\%$ VARIATION $\times 10 /$ Desired CV

\section{Interpretation}

\begin{tabular}{ll}
\hline$<100$ & Very Good \\
\hline $100-150$ & Good \\
$150-200$ & Satisfactory \\
\hline 200 & Not Acceptable \\
$\geq 2.0$ & $\begin{array}{l}\text { Unacceptable Performance. Remedial action usually } \\
\text { required. }\end{array}$ \\
\hline
\end{tabular}

- VIS values for each parameter for every month and similarly overall mean of VIS (OMVIS) must be calculated on monthly basis. OMVIS $<100$ indicates that results are very close to the target value and is very good. OMVIS in the range of 150-200 indicates need to take care of those parameters for which the reported values are very different from the target value for that particular method. OMVIS > 250 indicates reporting many wrong results and urgent steps to locate the problem must be taken followed by suitable corrective measures.

\section{Precision Index (PI)}

$\mathrm{PI}=$ Standard deviation of laboratory/Standard deviation of peer group

The control limits of $\mathrm{PI}$ are $<2$; chart is similar to SDI chart

The combined SDI/CVR chart has the ability to evaluate the total analyte's performance (precision and accuracy)

4. Coefficient of Variation Ratio (CVR) $=$ CV of laboratory month/CV of peer group month

- The combined SDI/CVR chart has the ability to evaluate the total analyte's performance (precision and accuracy). ${ }^{16}$

\section{Youden Plot}

Youden plot is a rectangular chart of which the four angles correspond to the control limits of the two control levels (-4SD - +4SD). EQAS schemes use two control samples of different levels in order to check the performance of the analytical method in different concentration/activities, and preferably close to the decision limits. The chart consist of 3 distinct parts, namely the acceptable part, the grey-zone and the rejected part which is denoted by different colors. Each dot represents a different laboratory and therefore Youden plot describes the whole EQAS scheme. There are dots which represents individual laboratory participating in the EQA programme. Dots (laboratories) that lie across the diagonal of the rectangular, at 45o, but are far for the center correspond to laboratories with proportional

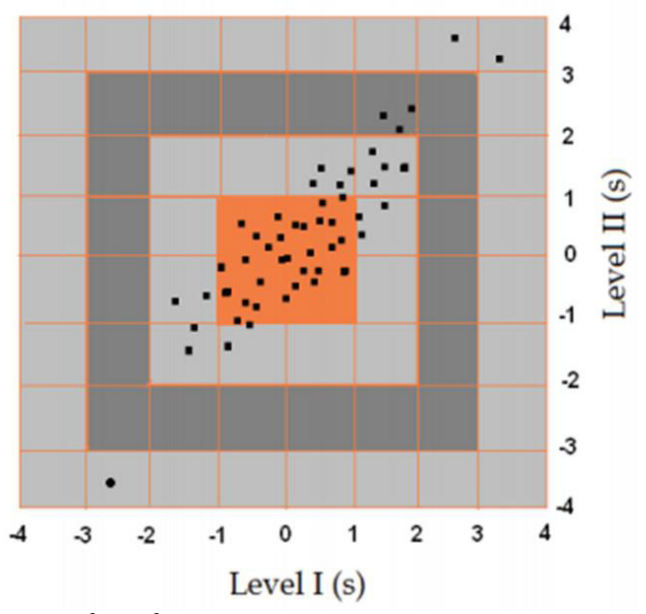

Figure 1. Youden Plot

Adapted from Karkalousos P, Evangelopoulos $\mathrm{A}^{48}$

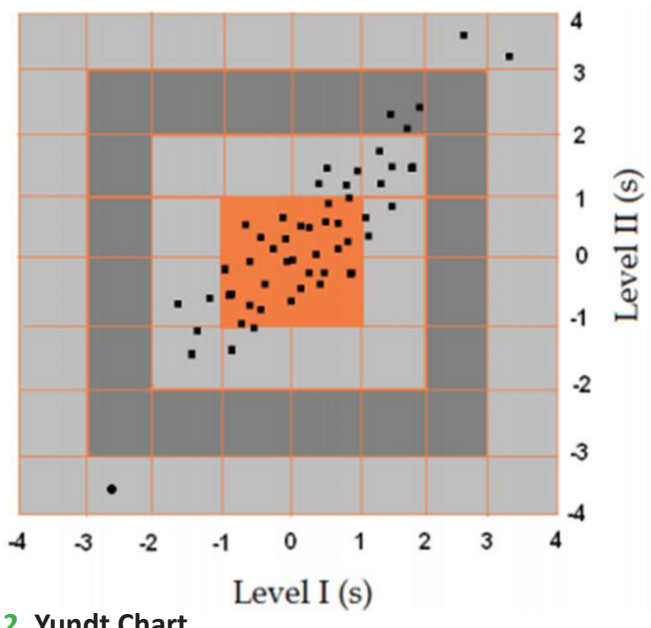

Figure 2. Yundt Chart

Adapted from Karkalousos P, Evangelopoulos $A^{48}$

analytical error. The greater the distance from the center, the greater the proportional error. Dots restricted in the central rectangular, correspond to laboratories of which the performance is considered acceptable for this specific analyte as depicted in fig. 2.16,17,48

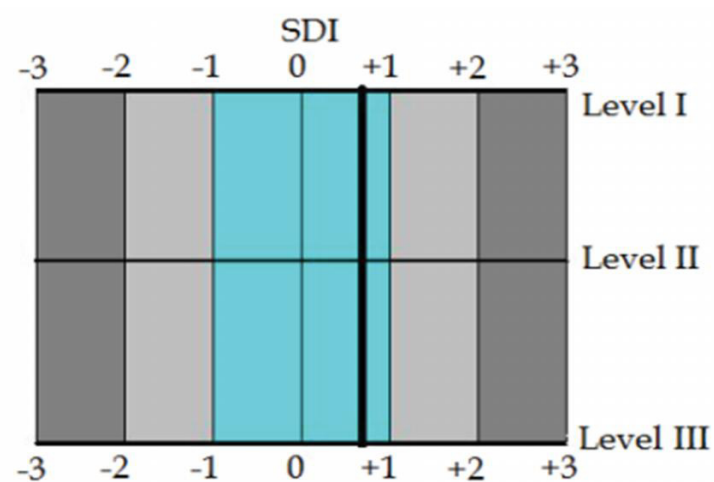

Figure 3. SDI Chart

\section{Yundt Chart}

It is a statistical chart useful for the determination of the performance of an analytical method across all its measuring range. For the plotting of a Yundt chart, at least three control levels needs to be plotted. If the line 
across the dots of the three levels is a straight one then the laboratory has a very good linearity. If not, there may be several issues with the linearity of the method. ${ }^{16,49}$ Yundt chart has been described in fig. 3 .

\section{EQA programs in Nepal}

The tertiary care centres and the clinical laboratories in Nepal with higher sample load are associated with the EQA programs provided by Nepal, India, Australia, etc. ${ }^{50-53}$ The most commonly employed EQA program is with Nepal Public Health laboratory (NPHL) Teku and Christian Medical College Vellore, India. ${ }^{50,51}$ Other EQA program is offered by Asian Network for Clinical Laboratory Standardization and Harmonization, Asian Quality Assurance Survey Program and from commercial companies like Bio-Rad and RANDOX. ${ }^{53,54}$ Till date, there is not any accrediting body in Nepal which accredits its own clinical laboratories and conduct EQA program independently.

EQA program plays a vital role in the improvement of the efficiency of a laboratory service. It helps in optimizing the overall quality of a health care system in terms of performance evaluation, patient care and safety issues, and overall quality of laboratory practices. It ensures that the participating labs in order to obtain quality test results and to get confidence in generating a reliable report should have best performance of instrument, updated and qualified staffs, use only good quality kits and store suitably. We have to establish our own accrediting body in Nepal and independently start our EQA program without relying for international bodies.

\section{List of few EQA centre for EQA participation in South East Asia}

India

- The National Accreditation Board for Testing and Calibration Laboratories (NABL)

- Christian Medical College (Vellore)

Indonesia

- The National Accreditation Committee (KAN)

Thailand

- The Bureau of Laboratory Quality and Standards (BLQS

- International Laboratory Accreditation Cooperation (ILAC)

- Asia Pacific Laboratory Accreditation Cooperation (APLAC)

\section{REFERENCES}

1. Belk WP, Sunderman FW. A survey of the accuracy of chemical analyses in clinical laboratories. Am J Clin Pathol. 1947; 17: 853-96. https://doi.org/10.1093/ajcp/17.11.853.

2. Libeer JC, Baadenhuijsen H, Fraser CG, Petersen PH, Ricos C, Stockl $D$, et al. Characterization and classification of external quality assessment schemes (EQA) according to objectives such as evaluation of method and participant bias and standard deviation. External Quality Assessment (EQA) Working Group A on Analytical Goals in Laboratory Medicine. Eur J Clin Chem Clin Biochem. 1996; 34:665-78.

3. International Organization for Standardization. ISO 15189: medical laboratories: particular requirements for quality and competence. Geneva, Switzerland: International Organization for Standardization; 2012.

4. World Health Organization. Quality Management System in the Laboratory: Manual; 2016.

5. Valdivieso V, Quesda R. Quality Management Systems for Laboratories and External Quality Assurance Programs. In: Quality Control in Laboratory. 2018: 21-34.

6. Rafael J, Mateo C. Quality Trends. 2009. Available from: http:// qualitytrends.squalitas. com

7. Yadav R, Bhartiya JP, Verma SK, Nandkeoliar MK. External quality assessment scheme (EQAS) our experience as a participating laboratory. IJRRMS. 2013; (4): 1-4.

8. Yerram S Sripad DV, Prabodh VS. External Quality Assurance Scheme (EQAS): Criteria for evaluating performance of a Laboratory. IOSR Journal of Biotechnology and Biochemistry (IOSR-JBB). 2018; 4(4): 16-20.

9. Libeer J-C. Role of external quality assurance schemes in 297 assessing and improving quality in medical laboratories. Clin Chim Acta. 2001; 309:173-7.

10. James D, Ames D, Lopez B, Still R, Simpson W, Twomey P. External quality assessment: best practice. J Clin Pathol. 2014; 67(8): 651-5.

11. Clinical Laboratory Improvement Amendments (CLIA) of 1988, US Public Law 100-575.

12. Cembrowski GS, Vanderline RE. Survey of special practices associated with College of American Pathologists proficiency testing in the Commonwealth of Pennsylvania. Arch Pathol Lab med. 1988; 112: 374-7.

13. Libeer J-C, Baadenhuijsen H, Fraser C, Hyltoft Petersen P, Ricos C, StockI D, Thienpoint L. Characterization and classification of external quality assessment Schemes (EQA) according to objectives such as evaluation of method and participant bias and standard deviation. Eur J Clin Chem Clin Biochem. 1996; 34: 665-78.

14. BS EN 14136:2004: Use of external quality assessment schemes in the assessment of the performance of in vitro diagnostic products. British Standards Institute. 
15. Directive 98/79/EC of the European Parliament and the Council of 27 October 1998 on in vitro diagnostic medical devices. Official Journal of the European Communities. 7.12.98, L331/ 1-37.

16. Ornemark U, Fostel H, Straub R, van de Kreeke J. Policies, requirements and surveys concerning frequency for participation in proficiency testing schemes. Accred Qual Assur. 2004;320(9):729-32.

17. ILAC Policy for Participation in National and International Proficiency Testing Activities. ILAC-P9:2005.

18. EA policy for participation in national and international proficiency testing activities. EA-2/10:2001.

19. International Organization for Standardization (ISO). Medical laboratories - particular requirements for quality and competence. ISO 15189:2012.

20. Ceriotti F. The role of external quality assessment schemes in monitoring and improving the standardization process. Clin Chim Acta. 2014; 432: 77-81.

21. Kristensen GBB, Meijer P. Interpretation of EQA results and EQAbased trouble shooting. Biochemia Medica. 2017;27(1):49-62.

22. Libeer JC, Baadenhuijsen H, Fraser CG, Petersen PH, Ricos C, StockI D, et al. Characterization and classifcation of external quality assessment schemes (EQA) according to objectives such as evaluation of method and participant bias and standard deviation. External Quality Assessment (EQA) Working Group A on Analytical Goals in Laboratory Medicine. Eur J Clin Chem Clin Biochem. 1996;34:665-78.

23. Miller WG, Jones GR, Horowitz GL, Weykamp C. Proficiency testing/ external quality assessment: current challenges and future directions. Clin Chem. 2011;57:1670-80.

24. Kristensen GB, Christensen NG, Thue G, Sandberg S. Betweenlot variation in external quality assessment of glucose: clinical importance and effect on participant performance evaluation. Clin Chem. 2005;51: 1632-6.

25. Miller WG, Myers GL, Rej R. Why commutability matters. Clin Chem. 2006; 52:553-4.

26. Vesper HW, Miller WG, Myers GL. Reference materials and commutability. Clin Biochem Rev. 2007;28: 139-47.

27. Kristensen GB, Rustad P, Berg JP, Aakre KM. Analytical Bias Exceeding Desirable Quality Goal in 4 out of 5 Common Immunoassays: Results of a Native Single Serum Sample External Quality Assessment Program for Cobalamin, Folate, Ferritin, Thyroid-Stimulating Hormone, and Free T4 Analyses. Clin Chem. 2016; 62: 1255-63.

28. Middle JG, Libeer JC, Malakhov V, Penttila I. Characterisation and evaluation of external quality assessment scheme serum. Discussion paper from the European External Quality Assessment (EQA) Organisers Working Group C. Clin Chem Lab Med. 1998;36: 119-30.

29. Hens K, Berth M, Armbruster D, Westgard S. Sigma metrics used to assess analytical quality of clinical chemistry assays: importance of the allowable total error (TEa) target. Clin Chem Lab Med. 2014;52: 973-980.
30. Sandberg S, Fraser CG, Horvath AR, Jansen R, Jones G, Oosterhuis $W$, et al. Defining analytical performance specifcations: Consensus Statement from the $1^{\text {st }}$ Strategic Conference of the European Federation of Clinical Chemistry and Laboratory Medicine. Clin Chem Lab Med. 2015;53:833-5.

31. Westgard JO. Useful measures and models for analytical quality management in medical laboratories. Clin Chem Lab Med. 2016;54:223-33. https://doi.org/ 10.1515/cclm-2015- 0710.

32. Stavelin A, Riksheim BO, Christensen NG, Sandberg S. The Importance of Reagent Lot Registration in External Quality Assurance/Profciency Testing Schemes. Clin Chem. 2016;62:708-15.

33. Panteghini M, Sandberg S. Defning analytical performance specifications 15 years after the Stockholm conference. Clin Chem Lab Med. 2015;53:829-32.

34. International Organization for Standardization. Stastistical methods for use in profciency testing by interlaboratory comparisons. ISO 13528. Geneva, Switzerland: International Organization for Standardization; 2005

35. Ricos C, Baadenhuijsen $H$, Libeer CJ, Petersen PH, Stockl D, Thienpont $L$, et al. External quality assessment: currently used criteria for evaluating performance in European countries, and criteria for future harmonization. Eur J Clin Chem Clin Biochem. 1996; 34: 159-65.

36. Kristensen GBB, Moberg Aakre K, Kristoffersen AH, Sandberg S. How to conduct External Quality Assessment Schemes for the preanalytical phase? Biochem Med (Zagreb) 2014; 24: 114-22.

37. Sciacovelli L, O’Kane M, Skaik YA, Caciagli P, Pellegrini C, Da Rin G. et al. Quality Indicators in Laboratory Medicine: from theory to practice. Clin Chem Lab Med. 2011; 49: 835-44.

38. Shahangian S, Snyder SR. Laboratory medicine quality indicators: a review of the literature. Am J Clin Pathol. 2009; 131:418-31.

39. Jamtsho R, Nuchpramool W. Implementation of External Quality Assessment Scheme in Clinical Chemistry for District Laboratories in Bhutan. Ind J Clin Biochem. 2012; 27(3): 300-5.

40. Thompson M, Ellison SLR, Wood R. The international harmonized protocol for the proficiency testing of analytical chemistry. IUPAC. $2006 ; 78(1): 45-96$

41. Deom A, Aouad RE, Heuck CC, Kumari S, Lewis SM, Uldall A, et al. Requirements and guidance for external quality assessment schemes for the health laboratory. $2^{\text {nd }}$ ed. Geneva: WHO; 1999:1-65

42. Sciacovelli L, Zardo L, Secchiero S, Plebani M. Quality specifications in EQAS: from theory to practice. Clin Chim Acta. 2004;346:87-97.

43. Miller WG, Myers GL, Ashwood ER, et al. State of the art in trueness and interlaboratory harmonization for 10 analytes in general clinical chemistry. Arch Pathol Lab Med. 2008;132:838-46.

44. Férard G, Dybkaer R. On the behalf of the IFCC and IUPAC Joint Committee for Nomenclature, Properties and Unit (C-NPU). Recommendations for clinical laboratory science reports regarding properties, units, and symbols: the NPU format. Clin Chem Lab Med. 2013;51:959-66 
45. Bossuyt $X$, Louche $C$, Wiik A. Standardisation in clinical laboratory medicine: an ethical reflection. Ann Rheum Dis. 2008;67:1061-3.

46. Clinical and Laboratory Standards Institute (CLSI). Using Proficiency Testing to improve Clinical Laboratory - Approved Guideline, $2^{\text {nd }}$ ed. GP27-A2. 2007.

47. Clinical and Laboratory Standards Institute (CLSI). Assessment of laboratory tests when proficiency testing is not available. Approved Guideline, $2^{\text {nd }}$ ed. GP29-A2. 2008

48. Karkalousos P, Evangelopoulos A. Quality Control in Clinical Laboratories, Applications and Experiences of Quality Control, Prof. Ognyan Ivanov (Ed.). 2011; ISBN: 978-953-307-236-4.

49. Klee GG and Westgard J.O. Quality Management. In: Teitz Textbook of Clinical Chemistry and Molecular Diagnostics, pp. 163-203, Elsevier Publishers, Philadelphia, Pa, USA, $5^{\text {th }}$ ed. 2013.
50. National public health laboratory, Ministry of health and Population Department of health Services, Government of Nepal.

51. Christian Medical College (CMC). EQAS program. http://home. cmcvellore.ac.in/clinqc/aboutEQAS.asx

52. Royal College of Pathologists of Australasia Quality Assurance Programs Pty Limited.www.rcpaqap.com.au.

53. https://www.bio-rad.com/en-np/category/external-qualityassurance-services eqas? ID $\quad$ 4971a64c-8419-44bd-a17abd18a308f0d9

54. https://www.randox.com/clinical-chemistry-eqa/ 